\title{
Local vs. Foreign Television Drama: Niche Analysis of a South Korean Audience's Use of Korean, American and Japanese Dramas
}

\author{
Byeng-Hee Chang \\ Department of Journalism and Mass Communication \\ Sungkyunkwan University, Seoul, 110745, South Korea \\ Hyoungkoo Khang \\ Department of Advertising and Public Relations \\ University of Alabama, Tuscaloosa, Alabama, 35487, USA \\ Irkwon Jeong \\ School of Communication \\ Kwangwoon University, Seoul, 139701, South Korea \\ Jin-Young Chung \\ Department of Journalism and Mass Communication \\ Sungkyunkwan University, Seoul, 110745, South Korea \\ Sang-Hyun Nam \\ Department of Journalism and Mass Communication \\ Sungkyunkwan University, Seoul, 110745, South Korea
}

\begin{abstract}
The present study explored the reception and consumption processes of a Korean audience's viewing of local and international television dramas. Findings indicated that the influential factors on the level of viewing in regards to Korean, American, and Japanese TV dramas among Korean viewers differed. In particular, a significant difference was found in terms of perceived drama characteristics. Applying niche theory, the present study also examined the audience's motivation for watching these television dramas. Results demonstrated that Korean TV dramas possessed the broadest niche breadth and were the most competitive. In a comparison of the perceived characteristics of TV dramas, American drama earned competitive superiority for most characteristics. The implications from the results were discussed in terms of cultural discount and proximity.
\end{abstract}

Key words: International Television Drama, Niche Theory, Motivation, Cultural Discount, Cultural Proximity.

\section{INTRODUCTION}

Television dramas became the decontextualized space for universal modes of storytelling [1]. Similar to other countries, television drama has been a popular source of cultural content in Korea. A survey of TV genre preference reports that drama competes with TV news for the first place [2]. Therefore, it is natural that various dramas, both foreign and domestic, are

* Corresponding author, Email: mediaboy@skku.edu Manuscript received Aug. 06, 2013; revised Oct. 04, 2013; accepted Oct. 14, 2013 broadcast in Korea due to their popularity. Until the mid-1980s, American dramas were more popular than Korean dramas. At that time, the material for Korean television drama was limited, so it could not satisfy Korean audiences [3]. However, since then, the production of Korean dramas increased and TV ratings soared, triggering a retreat of most American dramas from Korean terrestrial TV. In the mid-1990s, the emergence of cable channels specializing in drama brought about increased industrial demand for American dramas [4]. The increased supply resulted in the consumer boom for American dramas in the mid- and late 2000s, setting off a neologism, "Mee-De-Jok", which refers to the group of avid viewers of American drama in 
Korea. At that time, American blockbuster dramas like 'CSI' and 'Lost' received fervent response in Korean audience [3]. Nonetheless, Korean dramas generally earn two-digit TV ratings for terrestrial TV, while American drama tends to receive one-digit TV ratings. Other international TV dramas that garner a certain share of Korean TV ratings are Japanese dramas. These could not officially be imported into Korea until 2004 due to Korean government regulations. After its approval, however, Japanese dramas did not attract as much attention as American dramas, indicating trends in viewing behavior oriented around a small number of fans [4].

Despite the social, cultural and media industrial changes, academic research on the international distribution and consumption of TV dramas has been neglected. Most studies assessing the international distribution and consumption of cultural content has concentrated on movies. Studies on the overall distribution of TV programs have been partially conducted [5], though almost none of these studies have focused on drama. Moreover comparative studies assessing the factors influencing audiences' viewings of local and foreign dramas are even more challenging. In particular, empirical studies analyzing competitive relationships between local and international dramas are almost nonexistent.

The present research empirically investigates the viewing behavior of Koreans with regard to local and international TV dramas. First, the present study will explore and compare the factors that influence the viewing of local and international dramas. The present study will also analyze the competitive relationship between local and international dramas by applying niche theory. It provides a comparative superiority among the competitive medium.

\section{THEORETICAL BACKGROUND}

\subsection{International Flow of Cultural Goods}

Previous studies related to determinants of the use of international TV program focused mainly on economic factors, such as GDP and the scale of a country's broadcasting market [5]-[7]. Some scholars, however, pointed out that this type of economic approach does not sufficiently account for the international trade of cultural products. For instance, despite the economic development and the subsequent expansion of the universal values, traditional and cultural influences are said to still exist [8]. Studies then emerged that reflect each nation's cultural characteristics, as the counter plan for the problems raised. Studies in this venue adopted the concept of cultural discount [9] as a theoretical background.

Cultural discount implies that attractiveness or utilities decreases when cultural products from a certain cultural area flow into another cultural area. For example, when the language is different, the degree of comprehension may be distinct and cause a decline of attractiveness [10], [11]. Hence, we can assume that the audience prefers local television programs to international programs, when the programs bear similar patterns and similar qualities. Other than languages, previous studies (e.g., [12]) also used Hofstede's [13] cultural dimensions to measure the cultural distance between countries. Problems arose, however, regarding the reliability of
Hofstede's scale [14], and doubt as to whether such a cultural distance can be restored into the distance for content taste became apparent. Some scholars argued that empirical evidence for the influence of cultural distance [15]. Earlier economic and cultural approaches suggest that the international exchange of cultural content displays a solid one-way flow from America. The phenomenon, however, that the distribution of TV programs has been increasing in the areas or countries in Central and South America cannot be accounted for with such approaches. The notion of cultural proximity was suggested to describe the phenomenon. The concept poses that audiences prefer TV programs from a cultural area proximal to their own culture [16]. Based on this perspective, studies presented ways of identifying varied cultural areas [17], [18]. The cultural proximity cannot, however, fully explicate the case of Korea [19]. Rather than, for example, Japanese and Chinese cultural content, with relatively greater cultural proximity, American cultural content is consumed much more.

\subsection{Consumption of International Cultural Goods}

Previous studies on the international distribution and consumption of cultural content relied heavily on the macroscopic approach that sets up a country as an analysis unit. The macroscopic approach, however, draws upon an unrealistic assumption that consumers in a country are homogeneous [20].

In the microscopic approach, gender can be an influential variable making differences in the consumption of local and international cultural content. A study found, for example, that females have a greater tendency toward the consumption of different cultures compared to males [21]. A survey on the use of Telenovela from a Spanish American audience demonstrated that the viewing level of females was higher than that of male's [22]. Other variables, such as age, can be also associated with the consumption of cultural content. A study on the receptive process of American and Japanese TV programs in Taiwan [23] discovered that the mid-aged group between 30 and 54 tended to prefer American TV programs but seemed reluctant to watch Japanese TV programs, while the young group from 15 to 29year-old selected international TV programs, regardless of the origin of the cultural content. Education and income levels displaying the individual's social position can also influence the consumption of international cultural content. [23] suggests that Taiwanese prefer American TV programs, as their educational and income levels increase.

Psychographic variables related to individual characteristics can also influence the reception of international cultural content, which can, for example, influence the comprehension of international cultures [13]. As one accumulates much knowledge of international cultures, international cultures can be comprehended with ease and actively consumed. Future studies related to the comprehension of international cultures may concern the way in which direct experiences such as overseas trips [24] and indirect experiences through media [25] influence a country's image. Family can also influence the reception of TV dramas, as a form of environmental factor. For example, [26] showed that Korean audiences consider 'for all family members' and 'fun' as important criteria by which to select TV dramas for viewing. This finding indicates that Korean audiences have a tendency to 
regard TV dramas as content for the sake of family members, rather than for the sake of each individual.

\subsection{Niche Analysis of Motivations of Local and} International Television Dramas

A niche is the space in which media is situated in the multi-dimensional space with resources enclosing the media [27]. The resources include gratification, advertising revenues, consumer's time, and consumer's expenses. Previous studies applying niche theory focused firstly on advertising revenues that supported media firms' existence [28], [29]. With the concern about media users, their attention is turned to 'use and gratification' [30], [27]. The notion of gratification has been used in media studies based on uses and gratification theory [31]. That is, gratification factor is one of resources for media's survival.

Niche theory analyzes competitive relationships among media by way of three indices: niche breadth, niche overlap, and competitive superiority. These indices are the modification of conventional bio-ecological measures in [27]. Niche breadth refers to the diverse and broad use of resources given to certain media. From the perspective of motivation for TV drama, niche breadth presents the users' various motivations for watching TV dramas in a specific country. According to the notion of niche breadth, media (TV dramas by nation in this study) can be distinguished into specialists and generalists: Specialists have a narrow motivation, whereas generalists have a broad motivation. Hence, generalists are expected to have a greater chance to survive when new competition appears. Niche overlap indicates a similarity of resources used in two media, where the overlap of resources, an inverse measure, is significant when the value is low. From the perspective of motivation for drama use, overlap indicates the degree of similarity for audiences' motivation in the use of TV drama for two countries. That is, as the value is low (viz. overlap is large.), the value of competition is high. Competitive superiority is the index demonstrating the relative degree of resource uses among media. From the perspective of motivational dimension for dramas, the value of competitive superiority can be used to distinguish whether a certain country's drama has a relatively stronger motivation than another country's drama.

\subsection{Characteristics of Television Dramas}

The perceived characteristics of TV dramas can also influence the reception process. [32] distinguishes dramaattributes and users as the factors influencing TV drama ratings. The findings showed that the appearance of a celebrity in the drama has a positive impact on ratings regardless of gender. Conversely, the admiration of celebrities in American TV dramas was not a significant factor for motivation [33], according to which the factor of celebrity admiration has been the primary cause of preferring American TV dramas. But it did not play a major role in the viewing and evaluation of American dramas.

For American dramas, a distinct story turned out to be a significant factor for the ratings [33]. The findings indicate that local audiences seem to enjoy leisure time with international dramas that have uncommon stories and content not typically seen in local TV dramas. The findings also show that local audiences, who view international dramas with the motivation of unique stories and mood changes, tend to view them for a longer period at each viewing.

\section{RESEARCH QUESTIONS}

The purpose of the present study is to analyze and compare the reception and consumption processes of local TV dramas, as well as American and Japanese TV dramas. Japanese dramas have a relatively greater cultural proximity than American dramas, but American dramas have been consumed more in Korea. In economic view, this phenomenon can be explained. However, we still have a question regarding why Korean dramas based on the smaller scale of the broadcasting market are more popular than American or Japanese dramas. Therefore, the first research question is proposed as below:

RQ 1: Are there differences among Korean, American, and Japanese TV dramas with respect to the factors influencing the consumption of TV dramas?

Specifically, this study intends to analyze whether the motivation for watching TV dramas and the perceived characteristics by each country are similar or different for Korean, American, and Japanese TV dramas. Thus, the second research question is as follows:

RQ 2-1: In the motivational aspect of TV dramas, what is the nature of niche breadth, niche overlap, and competitive superiority among Korean, American, and Japanese TV dramas?

RQ2-2: Are there differences among Korean, American, and Japanese TV dramas from the attribute aspect of TV dramas?

We focus on the audiences' viewing motivation of TV dramas to analyze the competitive relationships among Korean, American, and Japanese TV dramas, by utilizing three indices of niche theory - niche breadth, niche overlap, and competitive superiority for RQ 2-1. We first extract characteristics, which are suitable for TV dramas, and analyze the differences in the degree of those characteristics among Korean, American, and Japanese TV dramas for RQ 2-2. Any differences will be analyzed to understand which country's TV drama occupies a superior position in which characteristics.

\section{RESEARCH METHOD}

\subsection{Variables}

Based on the RQ 1, dependent variables are suggested as viewing quantity of TV dramas by country and the attitude toward TV dramas by country. For the viewing quantity of TV dramas, since accuracy may be negatively affected when asking to recall the amount of TV drama viewed, the response to the 
question "I enjoy watching Korean (American, Japanese) dramas" was measured with a 5-point Likert scale (1 point: very unlikely, 5 points: very likely). The attitude toward TV dramas was also measured with the same of 5-point scale for the response of the question "I like Korean (American, Japanese) dramas."

Independent variables are the motivation for drama viewing and drama characteristics. A focus group interview and a pilot survey were conducted, as the motivation for drama viewing was not sufficiently available from previous studies. The present study extracted nine detailed motivations, which were utilized for the survey questionnaires, such as "I watch Korean (American, Japanese) dramas for fun, for a pastime, to see celebrities, for vicarious satisfaction, to understand the next episode, to capture the trend, to acquire topics for discourse, to relieve stress, and to rid myself of current difficulties." A 5point scale was used.

Based on the same procedure, the focus group interview and pilot survey, we could draw a total of ten characteristics for TV dramas, such as "Korean (American, Japanese) dramas have various stories, highly depend on celebrities, use much emotional appeal, bear a large scale, have diverse characters, have a high degree of completeness for screen and sound/music, exhibit superior acting skills, have a high degree of reality for expression modes, and have a fast unfolding of the plot". These were measured with a 5-point scale.

We adopted control variables that might affect the reception of international cultural content from previous studies. First, demographic variables marked the gender and numbers of family members living together. Age, education level, and income level that had a significant influence in earlier studies were not considered, because college student groups, which typically have highly homogeneous characteristics, were set up as the survey target. Considering that the comprehension of international culture and direct and indirect experiences on international cultures can influence the reception of cultural content, the reception variable for international cultures that embraces those variables was selected as a control variable. For the reception of international cultures, the questionnaire used "I like learning international cultures", "I can easily adopt international cultures" and "My lifestyle matches well to international cultures". A 5-point scale was used for measurement.

Exploratory factor analysis extracted two factors from nine questionnaires for the motivation regarding TV dramas. Table 1 presents the result of the reliability test for the variables.

Table 1. Measurement Item's Reliability

\begin{tabular}{cccc}
\hline Motivation & Drama & $\begin{array}{c}\text { Cronbach's } \\
\text { Alpha }\end{array}$ & $\begin{array}{c}\text { N of } \\
\text { Items }\end{array}$ \\
\hline Social & Korean & .723 & 4 \\
Social & U.S. & .806 & 4 \\
Social & Japanese & .861 & 4 \\
Individual & Korean & .510 & 4 \\
Individual & U.S. & .778 & 4 \\
Individual & Japanese & .819 & 4 \\
Reception of International & .800 & 3 \\
\multicolumn{2}{c}{ Cultural content } & & 3
\end{tabular}

One factor can be termed social motivations, with four items: "I watch Korean (American, Japanese) dramas for vicarious satisfaction, to capture the trend, to acquire topics for discourse, and to rid myself of current difficulties." The other factor is individual motivations including three items: "I watch Korean (American, Japanese) dramas for fun, for a pastime, and to understand the next episode." Two items "I watch Korean (American, Japanese) dramas to see celebrities and to rid myself of current difficulties" were excluded, as they were inconsistent in the two factors in regards to each country's drama.

\subsection{Data Collection}

A survey was conducted on college students during September to October 2008 to answer the research questions, considering that college students are avid consumers of local and international dramas [34]. 1,166 students from the major universities in Seoul, Korea participated in the survey. We excluded 137 incomplete responses. The study analyzed 1,029 responses, of which 439 were male $(42.9 \%)$ and 588 female (57.1\%). The average age was $22.8 .46 .6 \%$ of respondents were in a family size of four; the average number of family members was 3.2 .

\section{RESULTS}

\subsection{Comparison of Factors Affecting TV Drama Viewing}

Table 2 illustrates the factors influencing the level of Korean audiences' viewing of Korean, American, and Japanese TV dramas.

Table 2. Factors Influencing Watching Korean, American, and Japanese TV Dramas

\begin{tabular}{|c|c|c|c|}
\hline \multirow[b]{2}{*}{ Variables } & \multicolumn{3}{|c|}{ Beta coefficient } \\
\hline & $\begin{array}{c}\text { Korean } \\
\text { Drama }\end{array}$ & $\begin{array}{l}\text { U.S. } \\
\text { Drama }\end{array}$ & $\begin{array}{c}\text { Japan } \\
\text { Drama }\end{array}$ \\
\hline Social Motivation & $.110^{* *}$ & $.090^{* *}$ & $.173^{* *}$ \\
\hline Individual Motivation & $.374^{* *}$ & $.529^{* *}$ & $.492^{* *}$ \\
\hline Diversity of Story & $.115^{* *}$ & .044 & $.100^{* *}$ \\
\hline Reliance on Stars & $.069^{*}$ & -.036 & .007 \\
\hline Emotional Appeal & .029 & .056 & -.042 \\
\hline Large Scale & .055 & -.054 & -.038 \\
\hline Diversity of Characters & -.045 & -.039 & -.024 \\
\hline Technical Completeness & .044 & $.083^{*}$ & -.005 \\
\hline Completeness of plot & $.064^{*}$ & -.018 & -.013 \\
\hline $\begin{array}{l}\text { Acting Skills of } \\
\text { Actors/Actresses }\end{array}$ & .025 & .048 & .061 \\
\hline Reality of Expression Modes & .020 & .009 & -.048 \\
\hline Rate of Story Development & .002 & -.002 & $.133^{* *}$ \\
\hline $\begin{array}{l}\text { Reception of International } \\
\text { Cultural content }\end{array}$ & $-.059^{*}$ & $.082^{* *}$ & -.020 \\
\hline Gender & $.190^{* *}$ & $.060^{*}$ & $.105^{* *}$ \\
\hline $\begin{array}{l}\text { Number of Members in } \\
\text { Household }\end{array}$ & .010 & .004 & .034 \\
\hline $\mathrm{R}^{2}$ (F-value) & $\begin{array}{c}0.37^{* *} \\
(37.69)\end{array}$ & $\begin{array}{l}0.46^{* *} \\
(54.39)\end{array}$ & $\begin{array}{l}0.55^{* *} \\
(77.74)\end{array}$ \\
\hline
\end{tabular}


The analysis showed that significant differences were found in all cases with the motivation for drama viewing, but a far greater difference was found for perceived drama characteristics. For Korean dramas, story diversity, celebrity dependence and story completeness played significant roles for viewing level, while only technological completeness was a significant variable for American dramas. In contrast, story diversity and the rate of story development were significant for the viewing degree of Japanese dramas. The reception of international cultures induced a negative influence on the viewing level of Korean dramas and a positive influence on the viewing level of American dramas, while it did not play a role for Japanese dramas. Of the demographic variables, gender showed a significant influence on the viewing level in all analyses; the viewing level of females was greater than that of males in regards to dramas. For American dramas, the degree of significance was relatively lower than that of other countries' dramas. The number of family members living together was not significant in any cases.

Our analysis showed the same results as reported in previous studies in terms the significant effects of gender and celebrity dependence on the viewing level of TV dramas. However, our results additionally suggested that these effects could differ by TV drama's origins, such as local and foreign. Furthermore, our results showed new significant determinants of the viewing level of TV dramas, including 'diversity of story', 'technical completeness', 'completeness of plot', 'story development rate', and 'reception of international cultural content'.

\subsection{Niche Analysis of Motivations for Watching TV Dramas}

The second research question examines competitive relationships among Korean, American, and Japanese TV dramas in the aspect of viewing motivation, for which the indices for niche breadth, niche overlap, and competitive superiority were estimated by the factors of viewing motivation. This approach, which is based on the niche analysis, can provide different perspectives on the reception of consumers by examining competitive relationship more scientifically..

Table 3 compares niche breadths among three countries' TV dramas. Korean dramas had the highest niche breadth for social motivation and individual motivation. American dramas showed the next broadest niche breadth and Japanese dramas the narrowest.

Table 3. Niche Breadth of Use Motivations

\begin{tabular}{ccc}
\hline \multirow{2}{*}{ Drama type } & \multicolumn{2}{c}{ Motivations } \\
\cline { 2 - 3 } & Social & Individual \\
\hline Korean & .354 & .562 \\
U.S. & .297 & .471 \\
Japanese & .248 & .393 \\
\hline
\end{tabular}

Table 4 illustrates the degree of overlap of the viewing motivation between Korean, American, and Japanese TV dramas. The result shows that niche overlap was strongest between American dramas and Japanese dramas. Social motivation and individual motivation marked the lowest values between the two countries. Compared to Korean dramas, niche overlap was stronger with American dramas, rather than with Japanese dramas.

Table 4. Niche Overlap for Use Motivation

\begin{tabular}{ccc}
\hline \multirow{2}{*}{ Drama match } & \multicolumn{2}{c}{ Motivations } \\
\cline { 2 - 3 } & Social & Individual \\
\hline Korean - U.S. & .354 & .562 \\
Korean - Japanese & .297 & .471 \\
U.S. - Japanese & .248 & .393 \\
\hline
\end{tabular}

Observing the competitiveness of dramas by country (Table 5), Korean dramas had significant competitive superiority over American and Japanese dramas. American dramas also seemed to hold significant competitive superiority over Japanese dramas. In all aspect of the indices in niche analysis, the results showed that Korean drama has the strongest survivability and competitive superiority. It seems that local and international dramas are included in each different market. Like the finding of [33], viewing international dramas might be a way of enjoying leisure while viewing local dramas is a routine behavior.

Table 5. Comparison of Competitive Superiority of Use Motivation for Korean, American, and Japanese TV Dramas

\begin{tabular}{|c|c|c|c|c|}
\hline \multirow{2}{*}{ Drama match } & \multicolumn{2}{|c|}{$\begin{array}{c}\text { Social } \\
\text { Motivations }\end{array}$} & \multicolumn{2}{|c|}{$\begin{array}{c}\text { Individual } \\
\text { Motivations }\end{array}$} \\
\hline & $\begin{array}{l}\text { Superiority } \\
\text { value }\end{array}$ & $\mathrm{t}$ & $\begin{array}{c}\text { Superiority } \\
\text { value }\end{array}$ & $\mathrm{t}$ \\
\hline U.S. < Korean & 4.410 & \multirow{2}{*}{$8.723^{* * *}$} & 4.307 & \multirow{2}{*}{$8.862^{* * *}$} \\
\hline U.S. > Korean & 2.628 & & 2.497 & \\
\hline Japanese $<$ Korean & 5.208 & \multirow{2}{*}{$16.718^{* * *}$} & 5.505 & \multirow{2}{*}{$18.823^{* * *}$} \\
\hline Japanese $>$ Korean & 1.869 & & 1.801 & \\
\hline U.S. < Japanese & 2.116 & \multirow{2}{*}{$-7.778^{* * *}$} & 2.304 & \multirow{2}{*}{$-7.790^{* * *}$} \\
\hline U.S. > Japanese & 3.641 & & 3.952 & \\
\hline
\end{tabular}

\subsection{Comparison of TV Drama Properties}

The third research question compared perceived characteristics among Korean, American, and Japanese TV dramas. Ten items extracted from the focus group interview and the pilot survey was utilized for the comparison using average values for the t-tests (Table 6). Overall, American dramas were most competitive in eight categories. Korean dramas are most competitive from the aspects of dependence on celebrities and sentimental appeal.

Table 6. Comparison of Attributes of Korean, American, and Japanese TV Dramas

\begin{tabular}{cccc}
\hline Attributes & Drama & $\begin{array}{c}\text { Mean } \\
\text { difference }\end{array}$ & t-value \\
\hline \multirow{3}{*}{ Story Diversity } & Korean-U.S. & $-1.502^{* *}$ & -34.14 \\
& Korean-Japanese & $-.906^{* *}$ & -20.61 \\
& U.S.-Japanese & $.593^{* *}$ & 15.27 \\
\hline Reliance on Stars & Korean-U.S. & $1.587^{* *}$ & 45.56
\end{tabular}




\begin{tabular}{cccc} 
& Korean-Japanese & $1.000^{* *}$ & 27.02 \\
& U.S.-Japanese & $-.589^{* *}$ & -16.16 \\
\hline \multirow{4}{*}{ Emotional Appeal } & Korean-U.S. & $1.134^{* *}$ & 31.03 \\
& Korean-Japanese & $.569^{* *}$ & 15.67 \\
& U.S.-Japanese & $-.565^{* *}$ & -14.24 \\
\hline \multirow{2}{*}{ Large Scale } & Korean-U.S. & $-1.090^{* *}$ & -24.812 \\
& Korean-Japanese & $.256^{* *}$ & 7.27 \\
& U.S.-Japanese & $1.346^{* *}$ & 36.51 \\
\hline \multirow{2}{*}{ Character } & Korean-U.S. & $-1.405^{* *}$ & -30.47 \\
Diversity & Korean-Japanese & $-.772^{* *}$ & -17.71 \\
& U.S.-Japanese & $.628^{* *}$ & 15.09 \\
\hline \multirow{2}{*}{ Technical } & Korean-U.S. & $-.512^{* *}$ & -12.86 \\
Completeness & Korean-Japanese & 0.069 & 1.26 \\
& U.S.-Japanese & $.587^{* *}$ & 11.26 \\
\hline \multirow{2}{*}{ Plot } & Korean-U.S. & $-.902^{* *}$ & -22.34 \\
Completeness & Korean-Japanese & $-.177^{* *}$ & -4.71 \\
& U.S.-Japanese & $.726^{* *}$ & 20.63 \\
\hline \multirow{2}{*}{ Acting Skills } & Korean-U.S. & $-.286^{* *}$ & -7.78 \\
& Korean-Japanese & $.436^{* *}$ & 12.99 \\
& U.S.-Japanese & $.723^{* *}$ & 21.72 \\
\hline \multirow{2}{*}{ Reality of } & Korean-U.S. & $-.522^{* *}$ & -13.63 \\
Expression Modes & Korean-Japanese & $.114^{* *}$ & 3.12 \\
& U.S.-Japanese & $.633^{* *}$ & 17.6 \\
\hline \multirow{2}{*}{ Rate of Story } & Korean-U.S. & $-.469^{* *}$ & -11.12 \\
Development & Korean-Japanese & $-.106^{* *}$ & -2.5 \\
& U.S.-Japanese & $.362^{* *}$ & 9.57 \\
\hline \multirow{2}{*}{ p < 0.05, ${ }^{* *}<0.01$} & &
\end{tabular}

$\mathrm{p}<0.05,{ }^{* *} \mathrm{p}<0.01$

\section{DISCUSSIONS AND CONCLUSION}

Few studies have compared local dramas to international and systematically analyzed consumption processes and competitive relationships, although the consumption of international TV dramas has increased. The present study empirically analyzed whether Korean audiences exhibit a difference on the factors influencing the degree of viewing Korean, American, and Japanese TV dramas (RQ 1), how similar or different competitive relationships are between the countries' TV dramas in the aspect of viewing motivation (RQ 2 ), and whether a difference exists among the TV dramas of those countries from the perspective of perceived characteristics.

The present study has some noteworthy findings. First, a significant difference was found in the factors influencing the degree of viewing the countries' TV dramas. Specifically, all significant factors appeared to be different in the aspect of drama attributes. Especially for Korean dramas, the factors related to significant attributes were peculiarly noted, compared to American or Japanese dramas. These results point out that Korean audience tend to consider the attributes of local dramas rather appealing, when selecting a drama to view; it conversely implies that international dramas are subject to cultural discount. It should be noted that cultural reception is not significant for Japanese dramas. Such results imply that Korean audiences believe Japanese dramas to be somewhat proximal within the aspect of cultural proximity, subsequently out of consideration for cultural reception. Females have greater viewing time, but the relative degree for significance was low to some extent for American TV dramas. The findings can be reasoned in that American dramas portray male-oriented genre, such as crime and action. The number of family members was not significant; implying the family-unit viewing of dramas has gained generalizability.

Niche analysis of the motivation for TV dramas by country showed also some important implications. Korean dramas were broadest and Japanese dramas were the narrowest for niche breadth. The findings suggest that Korean dramas are being consumed in the most diverse way - the most general characteristics - within the aspect of use motivation. In contrast, since Japanese dramas represent the narrowest niche breadth, we might argue that it tends to be consumed by Japanese drama fanatics. Furthermore, the finding that Korean dramas utilize various resources indicates high survivability during a critical period, and the finding that Japanese dramas focus on specific resources suggests high efficiency for the use of (motivational) resources. The finding that niche overlap was strongest between American and Japanese dramas implies that the domestic TV drama market might be separated with the international TV drama market in the perception of Korean audiences. Korean TV dramas are supposed to compete with each other in the domestic TV drama market while American and Japanese TV dramas are supposed to compete with each other in the international TV drama market. In other words, Korean TV dramas do not seem to be a substitute of American or Japanese TV dramas while American TV dramas and Japanese TV dramas might be a close substitute with each other.

The third research question of the present study was to compare the perceived characteristics of each country's TV drama. The result presents America's superiority for most of the drama attributes. This corresponds to the account suggested from the economic approach related to the international exchange of cultural content. The economic approach will count America's superiority over the economies of scale and cultural content of other countries. The corollary is that America could maintain qualitative superiority of cultural content due to its massive capital investment in the production of cultural content based on such economies of scale. The result explains that an approach based on cultural discount can be superior to an approach based on cultural proximity in the Korean market. According to cultural discount, cultural content of a country with a large market size can consequently assume superiority in international exchange, while cultural content of a country with greater cultural relevancy assumes superiority in the competition, according to the approach of cultural proximity.

Interestingly, Korean dramas have higher ratings than American dramas in the Korean market, while it topped only two drama characteristics. We can mark two arguments on the results. First, the degree of influence on actual viewing can differ by drama characteristics. For example, the dependence of celebrities and sentimental appeal, showing the superiority of Korean dramas, can be key elements as to why a greater number of the Korean audience watches Korean TV dramas rather than American TV drama. Second, in terms of cultural discount, we can assume that local cultural content holds a superior position. Therefore, although audiences assess that 
Korean dramas are inferior to American dramas in terms of quality, they seem to prefer local dramas from the viewpoint of familiarity.

The present study puts its significance on the attempt to empirically analyze the reception and consumption processes of international TV dramas that have not been dealt with before. In particular, deviating from focusing on demographic factors, we introduced other affective factors, such as motivation and perceived drama characteristics. An interesting finding for the present study can be that the drama characteristics by country can influence the degree of viewing. In addition, the present study makes a substantial contribution to the field in that competitive relationships between local and international dramas have been empirically analyzed. Especially the present study adopted niche theory that was typically implemented in the analysis of competitive relationships between media in order to analyze the competitive relationships of TV dramas by country. Niche analysis showed that Japanese dramas are less competitive than the others. One of the reasons might be that Japanese dramas have fewer windows showing their contents. However, as new media such as smart TVs, which make it easier for content providers to access develop, cultural contents including television dramas can compete with each other in more equal conditions. An increase of access to foreign contents means a raise of audience size and social relations by it. Consequently the development of media technology might increase the access to foreign contents and change superiority in social motivation among three types of dramas.

Like other studies, the present study also exposed some limitations. First, the survey target was limited to college students, working as a constraint from the perspective of generalizability. Especially, since the survey group was homogeneous, a limitation was that some demographic factors, such as education level, were excluded in the analytic model. Second, our data was collected in 2008. It is difficult to reflect a rapid change and development of media technology. Finding how a relationship of competition among cultural contents is different by the change of media technology. There was also a limitation in comparing American and Japanese dramas as international dramas. American dramas were introduced to Korea in the 1960s, whereas Japanese dramas were not officially imported until the 2000s. Thus, Japanese dramas are in a disadvantageous situation from a historical perspective. Considering these limitations, future studies must broaden the target group and take into account the differences in the level of familiarization regarding American and Japanese dramas.

\section{REFERENCES}

[1] S. Ward and T. O'Regan, "Defining a national brand: Australian television drama and the global television market," Journal of Australian Studies, vol. 35, no. 1, Feb. 2011, pp. 33-47.

[2] Korea National Statistical Office (2008), 2008 Social Indicators in Korea (in Korean).

[3] B. S. Kim, "Why the audience is excited by American drama?," Forum and Site vol. 136, 2007, pp. 408-419.
[4] J. S. Yim, "An analysis of program familiarity in viewing of American TV fiction series in Korea," Korean Journal of Journalism \& Communication Studies, vol. 52, no. 3, 2008, pp. 53-75(in Korean).

[5] D. Waterman and E. Rogers, "The economics of televiseon program production and trade in far East Asia," Journal of Communication, vol. 44, no. 3, Sep. 1994, pp. 89-111.

[6] M, Dupagne and D. Waterman, "Determinants of U.S. television fiction imports in Western Europe," Journal of Broadcasting and Electronic Media, vol. 42, no. 2, Spring 1998, pp. 208-220.

[7] S. W. Lee, "Box-office market shares and consumer spending on movie in six countries: 1950 2002," Korean Journal of Journalism \& Communication Studies, vol. 48, no. 6, Dec. 2004, pp. 225-247.

[8] R. Inglehart and W. E. Baker, "Modernizations challenge to traditional values: Who's afraid of Ronald McDonald?," The Futurist, vol. 35, no. 2, 2001, pp. 16-21.

[9] C. Hoskins and R. Mirus, "Reasons for the U.S. dominance of the international trade in television programmes," Media, Culture, and Society, vol. 10, no. 4, Oct. 1988, pp. 499-515.

[10] C. Hoskins, S. McFadyen, and A. Finn, Global Television and Film, Oxford: Oxford University Press, 1997.

[11] B. M. Owen and S. S. Wildman, Video Economics. Cambridge, MA: Harvard University, 1992.

[12] S. Singh, "Cultural differences in, and influences on, consumers' propensity to adopt innovations," International Marketing Review, vol. 23, no. 2. 2006, pp. 173-191.

[13] G. Hofstede, Cultures and organizations: software of the mind, London: MacGraw, 1991.

[14] B. McSweeney, "Hofstede's model of national cultural differences and their consequences: A triumph of faith, a failure of analysis," Human Relations, Vol. 55, no. 1, Jan. 2002, pp. 89-108.

[15] S. McFadyen, C. Hoskins, and A. Finn, "Measuring the cultural discount in the price of exported US television programs," in V. A. Ginsburgh (Ed), Proc. $12^{\text {th }}$ international conference of the Association of Cultural Economics International, 2004.

[16] J. D. Straubhaar, Culture, language and social class in the globalization of television, In: Wang G, Goonasekera, A and Servaes J (Eds) The New Communication Landscape: Demystifying Media Globalization. London: Routledge, pp. 199-224, 2003.

[17] R. Inglehart and M. Carballo, "Does Latin America exist? (And is there a Confucian culture?): A global analysis of cross-cultural differences," Political Science and Politics, vol. 30, no. 1, Mar. 1997, pp. 34-47.

[18] S. Huntington, The Clash of Civilizations and the Remaking of World Order, New York: Simon and Schuster, 1996.

[19] Y. K. Chung, "Comparison of exposure, preference and attitude to foreign programs: for the application of cultural proximity concept in Asian context," Korean Journal of Journalism \& Communication Studies, vol. 48, no. 6, Dec. 2004, pp. 34-62. 
[20] K. Van Eijck, "Social differentiation in musical taste patterns," Social Forces, vol. 79, no. 3, Mar. 2001, pp. 1163-1185.

[21] E. Bihagen, "How do classes make use of their income?," Social Indicators Research, vol. 47, no. 2, Sep. 1999, pp. 119-151.

[22] Business Wire, Hooked on Telenovelas: ICR Survey Shows Plot is the Key to Viewership. Business Wire, May. 2005.

[23] K. Ishii, H. Su, and S. Watanabe, "Japanese and U.S. programs in Taiwan: New patterns in Taiwanese television," Journal of Broadcasting and Electronic Media, vol. 43, no. 3, Summer 1999, pp. 416-431.

[24] N. Papadopoulos and L.A. Heslop, Travel as a correlate of product and country images, in Muller, T. (Ed.), Marketing, (vol. 7), May. 1986, pp. 191-200.

[25] J. O'Shaughnessy and N. J. O'Shaughnessy, "Treating the Nation as a Brand: Some Neglected Issues," Journal of Macromarketing, vol. 20, no. 1, Jun. 2000, pp. 56-64.

[26] H. J. Lee, "Developing evaluation scales of television program quality according to genre," Korean Journal of Journalism \& Communication Studies, vol. 50, no. 3, Jun. 2006, pp. 424-451.

[27] J. W. Dimmick, S. Kline, and L. Stafford, "The gratification niches of personal E-mail and the telephone: Competition, displacement, and complementarity," Communication Research, vol. 27, no. 2, Apr. 2000, pp. 227-248

[28] J. W. Dimmick, S. J. Patterson, and A. B. Albarran, "Competition between the cable and broadcast industries: A niche analysis," Journal of Media Economics, vol. 5, no. 1, Jan. 1992, pp. 13-30.

[29] J. W. Dimmick and E. W. Rothenbuhler, Competitive displacement in the communication industries: New media in old environments, In: Rice RE (Ed) The New Media, Beverly Hills, CA: Sage, 1984, pp. 287-342.

[30] A .B. Albarran and J. W. Dimmick, "An assessment of utility and competitive superiority in the video entertainment industries," Journal of Media Economics, vol. 6, no. 2, Feb. 1993, pp. 42-57.

[31] J. G. Blumler and E. Katz, The Uses of Mass Communicat-ion, Beverly Hills, CA: Sage, 1974.

[32] J. A. Bae, "An Analysis on the Factors in Drama Rating: Focusing on the Drama Attributes and Audience Factors," Korean Journal of Broadcasting and Telecommunication Studies, vol. 19, no. 2, Jun. 2005, pp. 270-309.

[33] J. S. Lee and D. H. Rho, "The effect of viewing motivations on media choice and use: Focusing on college student's American drama consumption," Korean Journal of Broadcasting and Telecommunication Studies, vol. 22, no. 5, Oct. 2008, pp. 246-286.

[34] Y. J. Im, "A study on the uses and gratifications on the U.S. TV dramas: focusing on comparison to the Korean counterparts," Korean Journal of Communication and Information Studies, vol. 41, Feb. 2008, pp. 303-336.

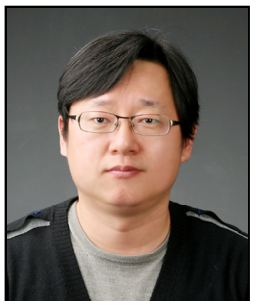

Byeng-Hee Chang

Dr. Chang is an associate professor in the department of Journalism and Mass Communication at Sungkyunkwan University, Korea. He received the Ph.D. degree in the department of telecommunication at University of Florida, U.S. in 2005. His research interests include contents usage behavior, contents marketing, and media economics.

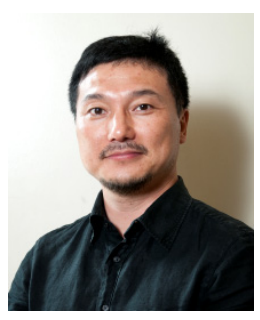

Hyoungkoo Khang

Dr. Khang received the Ph.D. in 2005 at the University of Florida, focusing his research interests primarily on political advertising, new media addiction, and political consumerism.

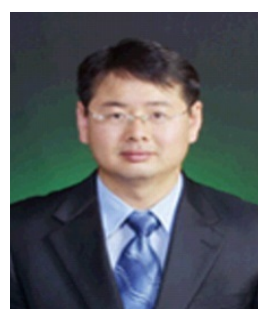

\section{Irkwon Jeong}

Irkwon Jeong is an associate professor in the School of Communication at Kwangwoon University in Seoul, Korea. He received his Ph.D. in Communication from Ohio State University. His publication includes "Blogging as "Recoding": A case study of the discursive war over the Navy Corvette Cheonan." E-mail: jeongik@kw.ac.kr

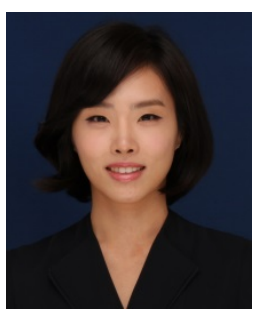

\section{Jin-Young Chung}

She is in the master's degree program in the department of Journalism and mass communication at Sungkyunkwan University, Korea. She is writing a master's thesis. Her main research interests include media contents and their effects on society including audience.

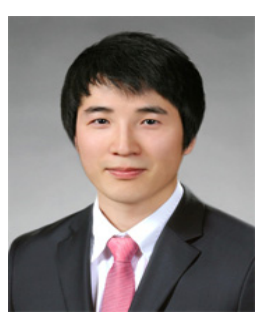

\section{Sang-Hyun Nam}

He received the master's degree in the department of Journalism and mass communication at Sungkyunkwan University, Korea in 2010 . He is currently a doctoral student at the same university. His main research interests include the effects of media and media contents on the behaviors of industry players in the context of media economics and management. 